\title{
Foreign report
}

\section{Psychiatry in Australia: economic and service delivery aspects*}

\author{
Gavin Andrews, Professor of Psychiatry, Clinical Research Unit for Anxiety Disorders, \\ University of New South Wales at St Vincent's Hospital, 299 Forbes Street, \\ Darlinghurst, NSW 2010, Australia
}

\section{The psychiatrists}

In 1987 there were 1,428 psychiatrists in Australia, 8.8 per 100,000 population (Burvill, 1988 ), $55 \%$ identified as in private practice and $45 \%$ in public sector practice. Let us be clear about terms. Public sector practice means that each week you receive a salary from the public purse whether you have seen one or a hundred patients. Private practice means that you are paid on a piece-work basis, also largely from the public purse (national health insurance or Medicare), but the income (at about $\$ 100$ per hour) depends exactly on the number of hours spent with patients. On average, private psychiatrists in Australia gross about $\$ 150,000$ per year, out of which they must pay practice expenses. The pay for public sector psychiatrists probably averages $\$ 70,000$ to which, for the purposes of our calculation, we will add the cost of rooms, telephone and secretary provided by the hospital which at $\$ 30,000$ brings the cost of a public sector psychiatrist to about $\$ 100,000$ per year. If $45 \%$ of psychiatrists are in public practice then the averaged cost of a psychiatrist in Australia can be calculated as $\$ 127,500$ per annum, and as there are 8.8 psychiatrists per 100,000 the cost, calculated on this simple basis, is $\$ 1.12$ million per 100,000 population (Andrews, 1989).

Australian psychiatrists have participated in two quite original projects. The first, the Quality Assurance Project (Quality Assurance Project, 1982) was designed to establish guidelines for the treatment of the commoner psychiatric disorders. The English language treatment outcome literature was searched and a summary of the results of empirical research was prepared. Concurrently, a sample of practising psychiatrists was asked about the treatment of patients described in short $\mathbf{4 0 0}$ word vignettes. As the final step in the process, experts in the disorder being studied were nominated, prepared their views

*Adapted from Andrews, G. (1990) Health services research and the future of Australian psychiatry. Australian and New Zealand Journal of Psychiatry, 24, 371-376. on treatment in writing, met in Sydney to consider the three sources of information, and then drew up guidelines for the treatment of the various disorders. The last of the ten treatment outlines, for antisocial personality disorder, should be published by the end of 1991.

We next surveyed the sample of psychiatrists to determine, from details of the last 20 patients seen, what psychiatrists actually did (Andrews \& HadziPavlovic, 1988; Andrews, 1989). Data on 1,904 patient consultations were obtained: $77 \%$ were seen in private, $23 \%$ in the public sector. Private patients were significantly more likely to be female, of working age, in the workforce, living with a spouse, and only $4 \%$ were in-patients at the time of the index consultation. Eighty per cent of public sector patients were of working age but only $18 \%$ were in the workforce, $40 \%$ were on pensions, significantly more lived in hostels, and indeed $37 \%$ were inpatients at the time of the index consultation. Public sector patients were judged to be significantly more impaired than the private patients. Half the patients in the public sector suffered a psychosis, mainly schizophrenia and organic psychoses. More than half the patients seen in private suffered from a neurosis or personality disorder, while only a quarter of the public sector patients received one of these diagnoses. Patients in the public sector were twice as likely to receive drugs, especially anti-psychotic medication, whereas private patients were twice as likely to be in psychotherapy, with insight psychotherapy being virtually confined to the private sector. Private patients were seen twice as often, were seen for longer each time, and indeed were expected to receive two and a half times as many consultation hours as patients in the public sector.

Psychiatrists in Australia were agreed about the treatment of the psychoses but there was less agreement on how to treat the neuroses (Andrews et al, 1987). If one estimates the number of patients in care and not the number of consultations, then a psychiatrist's case-load in terms of diagnoses is $\mathbf{4 0} \%$ psychoses, $40 \%$ neuroses, $6 \%$ personality disorders, and 
$6 \%$ child and adolescent diagnoses, a not altogether unreasonable state of affairs that reflects both the prevalence of these disorders in the community and their perceived seriousness.

This hybrid private/public method of funding psychiatrists does work, but there are problems. First, soon after qualification many psychiatrists tend to go into urban private practice and there are serious manpower shortages in the rural public sector. This problem would be reduced if access to national health service reimbursement was delayed in the overdoctored areas. The next problem is that patients in long-term dynamic psychotherapy average 330 hours of therapy and they are not always those most in need. As $7 \%$ of patients account for $50 \%$ of the private practice reimbursements, cost control might begin by reviewing these patients during the first year of therapy to determine the appropriateness of the planned psychotherapy. The third problem is the time-based method of reimbursement. Designed 20 years ago to support psychotherapy, it allows income to be maximised when a patient is seen repeatedly for 46 minutes. Difficult procedures like psychotherapy for borderline personality disorder, response prevention in obsessive compulsive disorder or careful diagnosis of an obscure organic condition return the same fee as endless sessions of empathy for patients seeking a meta-education. The most important problem is, however, that of continuing education for the practitioners. At present this is voluntary and poorly attended, even though recorded by the College. If medical defence premiums varied according to attendance, and if continuing education is effective there should be some obvious relationship, then many more would attend. Every doctor should be involved in continuing education.

\section{Hospital or community?}

Psychiatric hospitals perform their medical function as settings for the diagnosis and treatment of mental illness. Extreme dangerousness is a primary indication for hospital admission, but when investigations or treatments are needed that cannot be provided in the community then admission is also indicated. Many hospitals still perform a social role in providing shelter to those unable to gain shelter for themselves in our competitive society. This is a function that can be done more cheaply by other agencies, and while it may be humanitarian to care, it is not uniquely a medical responsibility. We need to develop clear ways of differentiating patients with psychiatric disorders from people who are stressed and miserable.

In 1987, Australia had 74 specialist psychiatric beds per 100,000 population. Seventy-five per cent were in state mental hospitals, $13 \%$ in general hospitals, and
$12 \%$ were in private hospitals. The recurring costs of a hospital service can be calculated in available bed day units at $\$ 150$ per day, the rate paid by health insurers to private hospitals. On this conservative basis (many public hospitals are more costly) then Australia with 74 beds per 100,000 is paying $\$ 4.05$ million per 100,000 population for psychiatric hospital care.

Psychiatric in-patient services are often the focus of criticism, and too often are either accused of wilfully detaining people and giving them harmful treatments, or blamed for not admitting some person who is acting abominably. I think we must accept that psychiatric hospital services are difficult to run and ask two questions. How can standards be assured? What are the alternatives to admission? The Australian Council on Health Care Standards has recently written explicit standards for psychiatric services. Most general hospitals are accredited, most private hospitals have been or are proceeding to accreditation, but accreditation of state mental hospitals is still the exception rather than the rule. All psychiatric hospitals should be accredited.

Community treatment can be an effective substitute for much hospital care. Hoult et al (1983) in Sydney, like many other groups throughout the world, have shown that if one is sufficiently well organised, the majority of acute psychiatric patients referred for admission to hospital can be treated in the community instead of in hospital. Furthermore, these programmes can achieve equivalent clinical improvement at a considerable cost saving, and both patients and their families report that such community care is more satisfying. We have recently reviewed the post-discharge status of long-stay severely ill patients placed in group homes in the community under the Richmond scheme in NSW (Andrews et al, 1990). We found that the patients preferred living in the community, no matter how spartan their community surroundings, and that their behaviour in the community was, by and large, very reasonable. Given the chronicity and impairment of the group selected for placement, I remain impressed as to how restorative life in the community has been for these one-time incurable patients.

In Australia, care in the community has meant the growth of community health services that usually rely on staff who are not medically qualified, not trained for the specific task and often quite uncertain of their professional roles and responsibilities. The current costs are quite substantial, in the order of $\$ 0.62$ million per 100,000 , quite similar to the cost of psychiatrists in full-time private practice. This budget provides for some 16 community mental health workers per 100,000 population, and these health professionals supervise group homes, conduct living skills centres, operate in 24-hour crisis teams, as well as offering consultation services from community mental health centre clinics. 
Australia appears to have one of the lowest bed ratios of any developed nation. As in many countries, the reduction in beds was hastened by the introduction of the therapeutic drugs, chlorpromazine, imipramine and lithium, and by community attitudes in the ' 60 s that rejected long-term admittance as a viable solution for the treatment of the mentally ill. The continuing reduction in psychiatric beds may have also been due to the increased community mental health services and to the increased number of private psychiatrists. This reduction in the number of psychiatric beds has important economic consequences. Ignoring for the moment the $14 \%$ of costs associated with investigations, drugs, and the community services, and adding together the costs of psychiatrists and hospital beds, services in Australia (8.8 psychiatrists@ @ \$127,500 each and 74 beds @ $\$ 54,750$ each) can be estimated at $\$ 5.17$ million per 100,000 population per year. Were Australia to adopt the New Zealand system (4.4 psychiatrists and 128 beds per 100,000 ) the cost would rise to $\$ 7.57$ million, while the United States system (16 psychiatrists and 113 beds) would cost $\$ 8.23$ million, and the English system (7.9 psychiatrists [identified as those with a College membership domiciled in England], and 142 beds), if adopted in Australia, would cost $\$ 8.78$ million per 100,000 simply because of the continuing reliance on admission to hospital as the primary means of service delivery in those countries. Thus these three overseas systems would cost an extra $40 \%$ were they to be introduced into Australia.

It is not that Australia has developed a system that is in any sense ideal. Three-quarters of the budget is still spent on hospitals even though three-quarters of patient consultations occur in the community. The problem in reallocating money is that hospitals offer tangible evidence, in terms of both buildings and professional hierarchies, that money is being spent on services. In contrast, community services, whether typified by the private psychiatrist's office or by the community mental health centre, are not the type of facilities that administrators find consistent with their needs for organisation and power. The most efficient system would be one in which the majority of staff and the majority of money were deployed in the community. We have calculated the cost saving that would flow from such an approach (Andrews, 1990) but have never understood how to gain access to the money saved by community care to reinvest in further services.

A further difficulty is that in the absence of any hospital type career structure that provides for rapid occupational advancement in return for expert service, there is little inducement for skilled personnel to work hard in a community service. The problem is common to all mental health professionals who consider working in the community, but can be illus- trated from the role of a community psychiatrist. When one is a trainee psychiatrist there are two attractive role models: the hospital specialists who never go anywhere without nurses or junior doctors to reaffirm their status, and the private practitioners who choose their own patients, their own rooms, their own secretaries and their own cars and are thus the masters of their working environment. Either role is satisfactory. However, the role of community psychiatrist is often not satisfactory. Most psychiatrists who consider working in this area would have to occupy another's office, make do with the hospital's secretary, drive the hospital car, and often be criticised for being unable to help unhelpable patients. Community psychiatrists are not in charge of their working environment nor, in terms of cost per patient seen, are they cheaper to society than their private counterparts, just less content.

In the next ten years I would suspect that many large mental hospitals will finally be closed. I have estimated from point prevalence and natural history data that given adequate community services 25 beds per 100,000 would suffice (Andrews, 1991). Psychiatric units in general hospitals should become high technology units for the investigation and diagnosis of acutely ill patients. The hostel functions that mental hospitals currently serve should be carried out more cheaply by group homes and other lower level accommodation in the community. In fact it will be the wise administrator who transfers hospital staff into the community and trades bed infrastructure for brain imaging equipment. If our bed requirements continue to contract over the next ten years we will be able to justify the formation of the expensive high technology diagnostic units that we will need when we unravel the biology of schizophrenia.

\section{References}

ANDREws, G. (1989) Private and public psychiatry: A comparison of two health care systems. American Journal of Psychiatry, 146, 881-886.

(1990) The cost of schizophrenia revisited. Proceedings of the First Workshop on Costs and Assessment in Psychiatry. Venice, 29-31 October.

- (1991) The Tolkien Report: A Plan for Model Psychiatric Services. Report to the NSW Department of Health, January.

- \& HADZI-PAVLOVIC, D. (1988) The work of Australian psychiatrists circa 1986. Australian and New Zealand Journal of Psychiatry, 22, 153-165.

- - Christensen, H. \& Mattick, R. (1987) Views of practising psychiatrists on the treatment of anxiety and somatoform disorders. American Journal of Psychiatry, 144, 1331-1334.

, Teesson, M., Stew'art, G. W. \& Hoult, J. (1990) Community placement of the chronic mentally ill. Hospital and Community Psychiatry, 41, 184-188. 
Burvill, P. W. (1988) A survey of the distribution of psychiatrists in Australia and New Zealand in 1987. Australian and New Zealand Journal of Psychiatry, 22, 436-447.

Hoult, J., Reynolds, I., Charbonneau-Powis, M., Weekes, P. \& Briggs, J. (1983) Psychiatric hospital versus community treatment: The results of a ran- domised trial. Australian and New Zealand Journal of Psychiatry, 17, 160-167.

Quality Assurance Project (1982) A methodology for preparing 'ideal' treatment outlines in psychiatry. Australian and New Zealand Journal of Psychiatry, 16, 153-158.

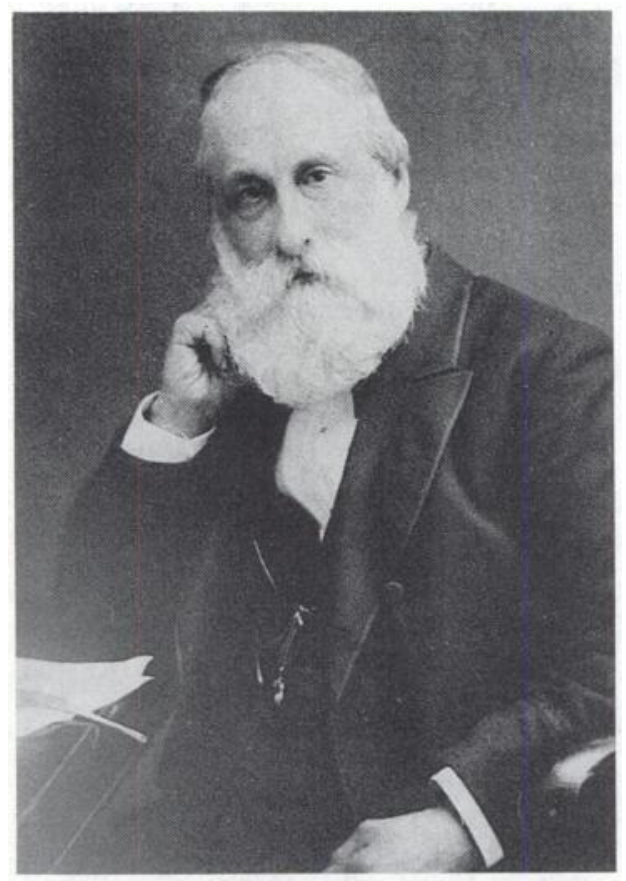

Daniel Hack Tuke (1827-1895)

Son of Samuel Tuke and great-grandson of William Tuke, founder of the York Retreat. Author, with Sir John C. Bucknill, of A Manual of Psychological Medicine, 1858. 